\title{
Biological effects of electromagnetic fields
}

\author{
Marko Markov
}

Published online: 16 April 2011

(C) Springer Science+Business Media, LLC 2011

In early 2000 I have received an invitation to attend the Millennium Workshop on Biological Effects of Electromagnetic Fields to be held in Greek Island of Crete. It turned to be a relatively small, but at high scientific level meeting organized by Prof. Panos Kostarakis and Ketty Apostolou. Two years later, we were again in that areathis time at the famous island of Rhodes, and then at the island of Kos, to return to Crete for the fourth Workshop in 2006. Prof. Kostarakis, who applied enormous efforts to congregate every other year scientists from up to 44 countries, suggested that the Workshop should be kept alive in the Mediterranean area and Prof. Antonio Lo Casto organized the fifth Workshop in Sicily. Last October, we were again in the Aegean See area-at ancient Turkish city of Bodrum. Prof. Tunaya Kalkan found the best resort in the world, Kefaluka hotel, just across from the Greek island of Kos.

Well, let me step out of science. The island of Kos is known to be the birthplace of Hippocrates, the father of medicine. Just $20 \mathrm{~km}$ from the island, on the western cost of Aegean Sea, was the ancient city of Halicarnassus (today Bodrum) in which Herodotus, the father of history was born. So, because of the Workshops we were able to see these important places in human history. If you add that the first and fourth Workshops were at Crete, the birthplace of Minoan Civilization, the residence of King Minos, the picture is even more impressive.

Actually, Kos has a very important role in my story. It was the last day of the Workshop and I did look again on the posters. I was approached by Dr. Peter Kevan

M. Markov ( $\square)$

Research International, Williamsville, NY, USA

e-mail: msmarkov@aol.com who introduced himself as the Editor-in-Chief of journal The Environmentalist. He told me that the presentations in this meeting were very impressive and offered to create a special issue of the journal with selected papers. Frankly, by this moment, I knew nothing about this journal. However, I found that this is a good recognition for our efforts in this area of science and quickly agreed. With Dr. Kostarakis we took the duty and a year later, in 2005 the first special issue "Biological effects of electromagnetic fields" was published. Then in 2007, we published the second one (following the 2006 Crete Workshop). In 2009 the third issue was on line within five months, and now after similar time period, we were able to offer to the attention of the readership of the journal the fourth issue.

This special issue is the hand of our readers who will judge the work done. But I must point several things. First, I want to thank Dr. Peter Kevan for the continuous support in publication of the papers about the effects of electromagnetic fields on human life and their importance for the biosphere. Second, during a decade, the Workshops were sponsored by international organizations as Bioelectromagnetics Society (BEMS), European Bioelectromagnetics Association (EBEA), Institute of Electrical and Electronics Engineers (IEEE) as well as the local governments and various industrial entities. This allowed to keep the cost low and to offer financial support for young scientists. The number of participating countries reaches 44 with up to 348 participants. We hosted scientists from Australia and Japan, from Iran and Egypt, from Brazil and Bulgaria.

The topics of presentations and published in the special issue papers covered the effects of electromagnetic field on human health and on environment, engineering and dosimetry of devices, standards and social policy, basic 
science and clinical application, electroporation and wireless communications.

This series of meetings do not belong to any particular organization or country, they belong to participants. This unusual approach allowed to keep the meetings into Mediterranean area and to provide opportunity for young people and scientists from small countries to joint the international research community. To conclude, the Seventh Workshop will take place in October 2012 at the island of Malta. Mark your calendar.

\section{References}

Biological effects of electromagnetic fields. The Environmentalist 25(2-4):65-263 (2005)

Biological effects of electromagnetic fields. The Environmentalist 27(4):387-605 (2007)

Biological effects of electromagnetic fields. The Environmentalist 29(2):107-269 (2009) 